\title{
CAPITALISMO Y SUBJETIVIDAD: ENTRE MOISHE POSTONE Y LEÓN ROZITCHNER
}

\author{
Emiliano Exposto, Gabriel Rodriguez Varela \\ Universidad de Buenos Aires \\ bttp://dx.doi.org/10.15304/ag.38.1.4541
}

\section{Resumen}

El artículo busca trazar una articulación entre la lógica del capital como sujeto de lo social y la formación histórica de la subjetividad. Para ello, proponemos una composición entre la relectura categorial respecto de Karl Marx que desarrolla el intelectual canadiense Moishe Postone y la interpretación filosófica sobre Sigmund Freud que elabora el pensador argentino León Rozitchner. En función de eso emprenderemos dos tareas. Primero, dilucidaremos el aparato conceptual de Postone centrándonos en su libro Tiempo, trabajo y dominación social (2006). Y luego, a la luz de la teoría crítica del capital realizaremos una lectura del concepto de subjetividad en Rozitchner tal como se presenta en Freud y los límites del individualismo burgués (1972) y Freud y el problema del poder (1985).

Palabras clave: Marxismo, Psicoanálisis, subjetividad.

\begin{abstract}
The article seeks to trace an articulation between the logic of capital as a subject of the social and the historical formation of subjectivity. To do this, we propose a composition between the categorical rereading of Karl Marx by the Canadian intellectual Moishe Postone and the philosophical interpretation of Sigmund Freud by the Argentine thinker León Rozitchner. Based on that we will undertake two tasks. First, we will elucidate the conceptual apparatus of Postone focusing on his book Time, work and social domination (2006). And then, in the light of the critical theory of capital, we will carry out a reading of the concept of subjectivity in Rozitchner as presented in Freud and the limits of bourgeois individualism (1972) and Freud and the problem of power (1985).
\end{abstract}

Keywords: Marxism, Psychoanalysis, subjectivity.

Recibido: 08/01/2018. Aceptado: 29/05/2018. 


\section{Introducción}

¿Por qué Marx y Freud, una vez más? ¿Por qué seguir intentando articular marxismo y psicoanálisis? Porque, tal como comentó Oscar Masotta en Conciencia y estructura (2010), el anudamiento entre tales herencias no es un capricho teórico, sino que constituye una necesidad concreta del objeto mismo: la convergencia entre lógica social generalizada y formación histórica de la subjetividad en condiciones capitalistas.

En el clásico texto Freud y Lacan de 1964 el intelectual francés Louis Althusser caracteriza al conjunto de las empresas teóricas que a lo largo del siglo XX pretendieron anudar las herencias del marxismo y del psicoanálisis como una larga historia de "confusiones", "reducciones" y "desviaciones" (Althusser, 2011, p. 82). Por esto mismo, y si bien no nos detendremos en este aspecto, dejamos sentado que nuestra búsqueda no puede desconocer los límites y alcances de los proyectos desplegados principalmente por el denominado "freudomarxismo" de William Reich, Herbert Marcuse o Erich Fromm. De igual modo que no resultaría pertinente desatender los proyectos de la llamada "izquierda freudiana" exponenciados en Vera Schmidt u Otto Fenichel, y más tarde en Jean-Josep Goux y Helmut Dahmer. En el "campo psi" argentino, los trabajos que emprendieron Enrique Pichón Rivère, José Bleger o Marie Langer también se registran como antecedentes claves de nuestras interrogaciones. Por último, nos hacemos eco de las críticas al "familiarismo" por parte de Gilles Deleuze y Felix Guattari en El Anti Edipo (1972) y a la "hipótesis represiva" en La voluntad de saber (1976) de Michel Foucault, puesto que ponen en primera escena algunos de los problemas que atañen a los mencionados programas teóricos que intentaron anudar marxismo y psicoanálisis durante el siglo pasado.

Es por ello que en la actualidad resulta pertinente detenerse en ciertas aclaraciones metodológicas. Para las cuales nos nutrimos en primer lugar de Marx y Freud en América Latina (2016) de Bruno Bosteels, quien luego de revisar los ensayos más audaces que se propusieron una composición entre las variables de ambas tradiciones propone la "lógica del desencuentro" como punto de partida epistemológico para peinar a contra pelo tanto la inmanencia de las obras marxianas y freudianas, como también los proyectos teóricos labrados en torno a sus pensamientos. Por otro lado, consideramos que una articulación entre los lenguajes del marxismo y el psicoanálisis debería asumir la heterogeneidad irreductible de los mismos (Grüner, 2013) y el carácter históricamente determinado de tales abstracciones socio-teóricas (Acha, 2007). La convergencia entre marxismo y psicoanálisis tendría que 
demorarse en la especificidad teórica de ambos archivos, en función de evitar construir un acoplamiento pleno y un sistema cerrado basado en simples equivalencias abstractas o paralelismos metafóricos. Es preciso mantener la tensión entre las nociones sistémicas y subjetivas, estructurales e históricas, y en lo que nos compete, procuramos soportar la fricción entre los análisis postonianos de la crítica de la economía política y la lectura rozitchneriana del psicoanálisis freudiano.

De nuestra parte, el cruce entre Postone y Rozitchner encuentra justificación dado que la propuesta postoniana de una crítica radical de la sociedad resulta indispensable para acceder a una renovada comprensión de las formas históricas mediante las cuales se producen relaciones impersonales de dominación y reificación del nexo social. No obstante, hallamos cierta vacancia en el planteo de Postone dado que carece, como gran parte de la tradición marxista, de una teoría sofisticada sobre los procesos inconscientes que facturan la subjetividad en el capitalismo. Por esto mismo, pretendemos contribuir a saldar esa vacancia realizando una interpretación de la teoría rozitchneriana de la subjetividad en el marco de la crítica de la lógica del capital. En el en el presente artículo, entonces, realizaremos en primer lugar una reconstrucción de los aportes cardinales de la relectura categorial que Postone opera sobre la crítica de la economía política marxiana, y en segundo lugar desplegaremos una interpretación de la concepción rozitchneriana de la subjetividad tomando como referencia las cifras de inteligibilidad de la teoría crítica del capital como sujeto histórico de la totalidad social.

\section{Postone y la crítica a la lógica del capital}

En Tiempo, Trabajo y dominación social (2006) el intelectual canadiense Moishe Postone escruta el archivo vivo de la herencia marxiana a contrapelo de las lecturas tradicionales del siglo XX, al mismo tiempo que logra ubicarse más allá de los llamados intentos post-marxistas o post-estructuralistas propuestos durante las últimas décadas. Lo que del proyecto teórico de Postone se elabora en la obra anteriormente referida, parafraseando a Bensaid, se ubica en el "archipiélago de los mil y un marxismos" bajo la forma de una "relectura categorial" (Postone, 2006, p. 17) de la crítica de la economía política elaborada por Karl Marx. Revistando entonces los cuadernos conocidos como Grundrisse y apostando por un renovado análisis de El Capital, esta relectura desemboca en una teoría crítico-radical de la sociedad capitalista que desborda las visiones historicistas, subjetivistas, o economistas imperantes en la heterogeneidad de la biblioteca marxista. 
Al interior de la llamada Teoría Crítica del Valor, el proyecto teórico postoniano oficia como una crítica radical, "auto-reflexiva y global" (Postone, 2006, p. 78) respecto de la moderna sociedad capitalista. El capitalismo es entendido entonces como una forma civilizatoria y un proceso relacional históricamente específico asociado a múltiples configuraciones, el cual da lugar a una totalidad social comandada por un principio mediador abstracto (el trabajo) y que posee una dinámica automática, cuasi-objetiva, impersonal y ciega (independiente de la voluntad de los individuos), pero que se sistematiza de manera contradictoria: "La idea de que las estructuras, las relaciones sociales subyacentes, de la sociedad moderna son contradictorias ofrece la base teórica de esa crítica histórica inmanente" (Postone, 2006, p. 143).

Sin ánimos de exhaustividad, y tomando en consideración fundamentalmente la articulación que perseguimos en este escrito, durante el presente apartado atenderemos sucintamente a los siguientes aportes dispensados por la teoría crítico-radical elaborada por Postone: a) una interpretación del legado marxiano que rompe con el marco historicista de la filosofía de la Historia Universal; b) una lectura de la obra marxiana que no la reduce al campo de la disciplina económica y a una teoría de la lucha de clases; c) una crítica del trabajo en el capitalismo opuesta a toda visión afirmativa, normativa y trans-histórica que emprenda una crítica a la sociedad "desde el punto de vista del trabajo" (Postone, 2006, p. 39); d) un cuestionamiento de la producción social en sí misma, y no solo una puesta en litigio de la distribución, intercambio desigual o propiedad de los productos sociales; e) una perspectiva a contrapelo del economicismo mecanicista de corte catastrofista y de cierto voluntarismo o subjetivismo sin historia; f) el asentamiento de cifras lógico-dialécticas para repensar fenómenos caros a la tradición marxista tales como la dominación, el antagonismo político o la lucha de clases, basándose en la mediación universalizada de formas capitalistas de objetivación y subjetivación; y por último, g) la negación de cualquier exterioridad o instancia socio-subjetiva predestinada a "debe ser" el sujeto revolucionario, y con ello, a no concebir al comunismo como la realización de una totalidad sino como la abolición de la misma.

Los aportes postonianos a la Teoría Crítica parten de afirmar la presencia en Marx de una crítica inmanente al capital entendiendo a este último como sujeto "automático y cuasi-objetivo" (Postone, 2006, p. 34) de una totalidad desgarrada e históricamente determinada. En contra del "marxismo tradicional” y el pos-estructuralismo, Postone señala que ambos comparten el hecho de tomar una "configuración históricamente especifica del 
capitalismo como esencia de la formación social" (Postone, 2006, p. 14). Para el intelectual canadiense no se trataría de elaborar "una teoría de aplicación universal sino una teoría crítica especifica de la sociedad capitalista" (Postone, 2006, p. 20), mediante la cual sea posible examinar los cambios históricos que se dan en la inmanencia de una lógica global propia de la modernidad capitalista, así como también cartografiar las "subjetividades históricamente cambiantes" (Postone, 2006, p. 19).

A través de esta concepción no afirma que el capital es una sistematicidad sin fisuras, ya que, al contrario, para Postone se trata de una lógica societal contradictoria. La dinámica reificada que adquiere el nexo social en condiciones capitalista es aquello que viabiliza la adopción de un signo tendencialmente totalista por parte de la sociedad. La mediación universalizada de todas las relaciones sociales por parte del capital es aquello que torna a este último en sujeto automático de un proceso histórico cuya lógica social adquiere características contradictorias y crecientemente abstractas e impersonales. Para penetrar en las categorías centrales de esa lógica social, Postone examina la sociedad capitalista a partir de las mutaciones que adquieren las formas de relación, producción, dominación y subjetivación desde su emergencia en la "Europa occidental" pasando por sus configuraciones mercantiles, fordistas, o del "Estado disciplinario-burocrático" hasta la composición actual de un capitalismo neoliberal globalizado.

Ahora bien, el proyecto teórico de Postone no se limita a realizar un estudio pormenorizado de la lógica interna que factura el desarrollo históricamente cambiante del capitalismo. A esto agrega una interpretación que busca superar las "familiares dicotomías teóricas de estructura y acción, sentido y vida material" (Postone, 2006, p. 20). Postone no analiza el capitalismo en términos de explotación, dominación concreta (personal o de grupo, por ejemplo) o propiedad privada de los medios de producción, sino como una interdependencia social objetiva y crecientemente abstracta, que al estar constituida por ciertas prácticas autonomizadas y cuasi-independientes de las voluntades y decisiones consientes, vehiculiza formas de subjetivación y reificación del nexo social que sujetan a los individuos a "imperativos y fuerzas estructurales e impersonales" (Postone, 2006, p. 20). Por consiguiente, no asistimos tanto a una teoría de la lucha de clases, o a una crítica sobre los modos de opresión y explotación, sino que encontramos principalmente una teoría critico-radical de la naturaleza misma de la modernidad basada en el análisis categorial de las formas duales de mediación social en la sociedad capitalista (especialmente, aquellas contenidas en las nociones marxianas de trabajo abstracto, ley del valor y forma-mercancía). 
El intelectual canadiense examina entonces la reificación de los vínculos sociales desde una visión que no los presenta como "relaciones interpersonales abiertas, sino como un conjunto de estructuras cuasi-independientes" (Postone, 2006, p. 185), postulando mecanismos universalizados de mediación social (el valor, el trabajo y la mercancía) y analizando, asimismo, sus consecuentes efectos fetichizantes en la confección objetiva de una dominación impersonal y de una subjetivación condenada al automatismo. El desafío de Postone es evitar tanto una afirmación de la modernidad "racionalista, universalista y abstracta" (Postone, 2006, p. 45), como así también eludir una crítica romántica, trans-histórica, "antiracionalista y antimoderna" (Postone, 2006, p. 45).

El proyecto teórico postoniano, entonces, pretende "redefinir las categorías marxianas de modo que puedan (...) abordar el núcleo de la totalidad social en tanto que contradictoria" (Postone, 2006, p. 18). A lo que agrega: "abordar no sólo el carácter contradictorio de la totalidad, sino también el fundamento de falta de libertad que la caracteriza" (Postone, 2006, p. 185). Por consiguiente, según el intelectual canadiense Marx no desarrolla una teoría de la producción material y de la estructura de clase. Al contrario, considera que el núcleo del proyecto marxiano consiste en una "teoría de la constitución histórica de determinadas formas, reificadas, de objetividad y subjetividad social" (Postone, 2006, p. 42), dónde las categorías de El capital dan cuenta de un análisis crítico, y por ende auto-flexivo, respecto de la singular historicidad de las "formas culturales y las estructuras sociales de la civilización capitalista" (Postone, 2006, p. 43).

Desde esta impronta conceptual, totalidad y dialéctica se convierten en categorías centrales de la obra de Postone. Las cuales no son concebidas por el autor como herramientas político-intelectuales de corte emancipatorias, sino en tanto nociones críticas y negativas. Tomando distancia de gran parte de la tradición marxista, presente por ejemplo en Historia y conciencia de clase (1923) de Lukács, Postone sostiene que "la negación histórica del capitalismo no conllevaría a la realización, sino a la abolición de la totalidad" (Postone, 2006, p. 133; cursivas originales). El intelectual canadiense afirma que si existe una totalidad es precisamente porque el capital es el sujeto de una lógica histórica -por ende: transitoria, no natural, ni divina- de automediación social impersonal y abstracta de carácter reificado. De manera que hay totalidad porque hay capitalismo. La crítica marxiana no se sostiene entonces desde el "punto de vista de la totalidad" (Postone, 2006, p. 264), puesto que conllevaría a postular una positividad exterior al capital como podrían ser el trabajo vivo, el proletariado o el ser genérico. 
Para Postone, en cambio, la crítica de la economía política analiza la subsunción (formal, material y tendencialmente real-total) de los individuos "bajo estructuras objetivas y abstractas" (Postone, 2006, p. 264).

Al mismo tiempo, la dialéctica no es el "arma de la crítica" con la cual cuenta el proletariado o la vanguardia revolucionaria ni tampoco la lógica nodal del "materialismo histórico". Para Postone si hay dialéctica es porque en el capitalismo se despliega una dinámica de mediación social reificada y conflictiva que atraviesa la estructura histórica. La dialéctica es la lógica históricamente determinada que admite lo social cuando se totaliza contradictoriamente en condiciones capitalistas.

Por esto mismo, el intelectual afirma que la totalidad nunca es una categoría normativa en cuyo desenvolvimiento positivo es posible hallar una potencia por parte de los dominados y oprimidos, adquiriendo en cambio una valoración crítica y negativa hacia el interior de su propuesta teórica. Por iguales razones es que la dialéctica no es concebida como una herramienta conceptual exterior a su objeto, o un proceso de la naturaleza a secas, sino que explicita el movimiento mismo del capital como sistema de "distancias históricas" (según veremos en Rozitchner) reproducidas automáticamente más allá de la voluntad y conciencia de los individuos.

El capital, entonces, no posee exterioridad: la clase, el trabajo vivo, el deseo o la dinámica parcial de las pulsiones no conforman ni un "afuera" ni una inversión ontológica respecto de la totalidad contradictoria constitutiva de la sociedad capitalista. Particularmente en lo que refiere a la noción marxiana del trabajo esta no oficia como resorte desde el cual desplegar una política emancipatoria, puesto que en el capitalismo la existencia del mismo queda supeditada a la auto-valorización del capital: "todo el proceso laboral entero se presenta como proceso que le es propio al capital mismo" (Postone, 2006, p. 232). Por lo tanto, Postone concibe al trabajo como el mediador universalizado en condiciones capitalistas, imputando las perspectivas marxistas que encuentran en aquel un fundamento ontológicamente trans-histórico desde donde combatir la dominación capitalista. No se trata entonces de sostener una crítica radical en presupuestos ontológicos y/o trans-históricos exteriores al capital. La cuestión no pasa por proponer una crítica al capitalismo desde el punto de vista del trabajo, puesto que, al contrario, la tarea es realizar una "crítica al trabajo en condiciones capitalistas" (Postone, 2006, p. 87).

Por esto mismo es que la contradicción que estructura la sociedad capitalista no está dada para Postone entre Capital versus Trabajo tal como ha estimado una buena parte de la tradición marxista del siglo XX. De acuer- 
do con el autor, las contradicciones son inmanentes a la totalidad dialéctica y negativa del capital. La lógica ciega y auto-propulsada del capital cercena las capacidades de auto-determinación de los individuos, pero a la vez vehiculiza potencialidades emancipadoras que no puede realizar. La pluralidad de tensiones que definen la totalidad desgarrada del capital (tiempo abstracto y tiempo concreto, por ejemplo) quedan supeditadas a la tensión que se produce entre riqueza y valor. Referimos a una contradicción que se da entre la creciente cualificación de las capacidades y atributos sociales, y el encorsetamiento de tal riqueza social debido a la mediación del valor como equivalente abstracto socialmente universalizado, por lo cual se encierra la riqueza material bajo la forma celular de la mercancía. Lo social, al ser motorizado por la universalización de las formas del capital como sujeto que se autonomiza y abstrae de las condiciones de vida concretas, es intrínsecamente contradictorio en la medida en que da lugar a "constricciones estructurales sobre la acción" (Postone, 2006, p. 94) al mismo tiempo que habilita posibilidades liberadoras.

El intelectual canadiense señala que para Marx en El Capital "la riqueza de las sociedades en que las que domina el modo de producción capitalista se presenta como un 'enorme cúmulo de mercancías', y la mercancía individual como la forma individual de esa riqueza" (Marx, 2012, p. 43). Ahora bien, Postone rescata otra concepción de la riqueza dispensada por Marx en los Grundrisse. A saber: "Si se despoja a la riqueza de su limitada forma burguesa, ¿qué es la riqueza sino la universalidad de las necesidades, capacidades, goces, fuerzas productivas, etc., de los individuos, creadas en el intercambio universal?” (Marx, 1971, p. 447). Marx se refiere a la posibilidad de una riqueza producto de la dinámica contradictoria de la sociedad capitalista, pero no limitada a la forma burguesa de la mercancía. Esta concepción crítico negativa de la riqueza se presenta como una punta para captar el núcleo de las fricciones en el capitalismo. La lógica social de la modernidad, poniendo al valor abstracto como forma mediadora generalizada, dinamiza y multiplica las capacidades, necesidades, saberes y atributos sociales, pero al mismo tiempo los subordina a la exterioridad abstracta de la ley del valor y de la riqueza como forma-mercancía. En la contradicción entre riqueza y valor, según Postone, se enfrenta el potencial transformador y abierto del capitalismo, y su configuración histórica como lógica social fetichista y reificada.

El capitalismo produce una riqueza material en permanente cuantificación y diversificación cualitativa, empero esta multiplicación del ser social queda detenida en su potencial despliegue dado que se realiza en forma 
reificada y fetichista por el dominio totalista de la forma del valor. Es por esto mismo que la crítica marxiana no aspira a realizar un ser genérico o una totalidad social obturada por la alienación o por el fetichismo de la mercancía, sino que implica imaginar procesos de subjetivación y disputas socio-políticas asumiendo nuestro estar constituidos por aquello mismo que buscamos enfrentar: el capitalismo.

Lo anteriormente expuesto conlleva para Postone a afirmar la ausencia en Marx de una teoría especulativa de la llamada "Historia Universal". Siendo entendida como una mirada retrospectiva y arbitraria, contingente pero puesta como necesaria y evolutiva por la modernidad capitalista, y que resulta en un concepto teleológico, racional y presuntamente neutral del "progreso" de la Humanidad. Para Postone en la medida que Marx señala la transitoriedad de las formas sociales de producción y dominación, lejos de afirmar una noción universal de la Historia elabora una crítica negativa y auto-reflexiva del concepto mismo de Historia en tanto categoría históricamente cambiante e históricamente determinada.

A partir de esta consideración, el trabajo de Postone apunta a disputar el orden singularmente histórico de determinaciones impersonales y automáticas que la lógica del capital impone sobre la acción humana y sus posibilidades de autodeterminación. La ausencia en Tiempo, trabajo y dominación social de resortes trans-históricos (el trabajo vivo o el ser genérico alienado), historicistas (Historia Universal), socio-economicistas (la clase como objetividad palpable), o subjetivistas (el proletariado definido a priori como sujeto redentor) dentro de la crítica radical sobre la moderna sociedad capitalista, posibilita asimismo eludir cualquier declaración universalista y a-histórica de una política comunista (base de la axiomática de la "idea comunista" en Alain Badiou); tanto como de la postulación abstracta de una "autonomía de lo político" (como en los post-marxismos de Jacques Rancière y Ernesto Laclau); y de las diferentes variantes del autonomismo que vislumbran sujetos externos al capital y el Estado (con matices en las versiones de Antonio Negri y John Holloway).

Así pues, Postone descubre en Marx una lógica social en la cual el capital es el sujeto de un proceso automático reproducido en y por las acciones humanas más allá de la voluntad y consciencia de los particulares. El meollo del argumento postoniano es que en el capitalismo el nexo social muta, puesto que las relaciones de dependencia personal directa o inmediatamente comunitarias (propias de una sociedad pre-capitalista) pasan a ser tendencialmente subordinadas bajo vínculos abstractos e impersonales. Para Postone, entonces, en la sociedad del capital se produce un conflicto don- 
de la emancipación del individuo con respecto a los lazos de dependencia personal o directa resultan ser el reverso de su sumisión a los mecanismos anónimos de la sociabilidad reificada.

La mutación del nexo social que Postone lee en Marx como específica del capitalismo no implica una historia lineal, evolutiva y siempre superadora respecto de los diversos modos históricos de producción o de las etapas de organización social del trabajo humano. Y esto debido a que para el intelectual canadiense el marxismo no es un economicismo. Por esto mismo, los conceptos de la economía política que se despliegan hacia el interior del archivo marxiano no deben ser entendidos como nociones económicas en sentido estrecho o disciplinar. Son categorías históricamente generadas e intrinsecamente problemáticas que emergen como formas de inteligibilidad comprensivas y auto-reflexivas que tienen el propósito de funcionar como una crítica radical e inmanente sobre la lógica social de capital.

Así como el marxismo no es un economicismo, tampoco resulta pasible de ser reducido a una teoría sobre la división social en clases sociales basada en la lucha de clases como motor de la historia, puesto que el "retorno a Marx" de Postone lejos esta de proponer un "hegelianismo materialista". La lectura marxista en términos de una "inversión materialista de la dialéctica", según el autor, lleva a la mistificación de construir sujetos "materiales" (la humanidad, el proletariado) predestinados ontológicamente a realizar en un futuro ( $\sin$ conflictos ni grieta subjetiva) la esencia genérica y liberada de una presunta totalidad alienada. Para Postone, en cambio, el pensamiento marxiano no ofrece sino una crítica inmanente respecto de las formas que adquiere el nexo social, la dominación impersonal y la subjetivación en la moderna sociedad capitalista.

La teoría crítica entonces se define por la capacidad para analizar el mundo constituido desde la perspectiva de las posibilidades liberadoras que lo habitan contradictoriamente. La dinámica totalista y dialéctica de la lógica social escrutada por Postone, a fin de cuentas, es aquella que da lugar a que las contradicciones estructurales del capitalismo fundamenten la posibilidad auto-reflexiva de una crítica inmanente radical y las potencialidades transformadoras de una emancipación.

\section{Rozitchner y la crítica a la construcción histórica de la subjetividad}

La teoría de la subjetividad elaborada por el argentino León Rozitchner articula categorías marxianas y concepciones freudianas para desembocar en una crítica filosófico-política respecto de la formación históricamente 
conflictiva de la subjetividad en el capitalismo. Durante las décadas de los setenta y ochenta, los textos Freud y los límites del individualismo burgués (1972) y Freud y el problema del poder (1985) muestran que la composición rozitchneriana entre Marx y Freud encuentra su eficacia en la interacción recíproca de la pregunta por la efectuación de lo histórico en el proceso subjetivo y por la búsqueda de un índice concreto que verifique la estructuración de lo subjetivo en el devenir objetivo.

En la primera parte de este trabajo nos servimos de los aportes dispensados por la "re-lectura categorial de Marx" desarrollada por el intelectual canadiense Moishe Postone para afirmar al capital como sujeto contradictorio de la totalidad social, cuyos efectos de dominación abstracta y determinación impersonal es preciso disputar para ampliar radicalmente la "autodeterminación colectiva" y "el horizonte de la política" (Postone, 2006, p. 94). En ese marco, en el presente apartado realizamos una lectura de la teoría rozitchneriana de la subjetividad a la luz de la crítica radical de la lógica del capital, ya que consideramos que la renovada "lectura filosófica” de Freud (Ricoeur, 2013, p. 186) que Rozitchner lleva adelante resulta fundamental para complejizar con las cifras de lo inconciente el análisis postoniano de las formas socio-subjetivas imperantes en la civilización capitalista. La concepción rozitchneriana sobre la subjetividad, según nuestra consideración, es importante para cualquier posición que se pretenda emancipatoria, no solamente en el sentido de modificar las condiciones objetivas (económico-sociales, que desde ya es ineludible), sino también a los efectos de dislocar la formación histórica de la subjetividad capitalista indagando en las posibilidades liberadoras que el movimiento del capital proporciona al mismo tiempo que inhibe en su realización.

La inclusión de las indagaciones rozitchnerianas en el seno de la teórica critica del capital está justificada en la medida en que el proyecto teórico del filósofo argentino parte de diagnosticar que la subjetividad humana es el "punto ciego" de la analítica marxiana, afirmando que "falta en ellos una teoría de la subjetividad que contenga en sus presupuestos mismos la densidad histórica del mundo que la organiza como tal" (Rozitchner, 2013, p. 13). Para el autor las elucidaciones marxistas sobre la dominación capitalista adolecen de una sofisticada teoría de la subjetividad, por lo que se sostienen en esquemas de inteligibilidad modernistas, racionalistas y conciencialistas que expresan su dificultad para concebir lo subjetivo más allá de las posiciones objetivas en el aparato productivo, los contendidos ideológicos de la conciencia y los intereses socio-económicos de la clase. Sin dejar de considerar la relevancia de tales preocupaciones, Rozitchner considera 
que estas teorías desembocan en posiciones "dónde los hombres aparecían solo como soportes de las determinaciones sociales porque no se elaboraba nada en ellos" (Rozitchner, 2013, p. 231).

Esto resulta importante porque Rozitchner parte del fracaso de las tentativas revolucionarias nacionales y continentales de la segunda mitad del siglo XX para desde allí "comprender cuál es el lugar, también individual, donde ese poder colectivo sigue de algún modo generándose y al mismo tiempo inhibiéndose en su desarrollo" (Rozitchner, 2013, p. 11). En ese sentido, uno de los escoyos fundamentales que el filósofo encuentra en ciertas vertientes del marxismo es precisamente no haberse hecho cargo, ni modificado, el modo en que se estructuran las múltiples contradicciones del sistema objetivo en el seno de nuestro propio sistema subjetivo. Según el filósofo argentino, la omisión de esta tarea hacia el interior del marxismo está estrechamente relacionada con la ineficacia de las empresas revolucionarias, dada la imposibilidad a la que conllevan para develar qué "determinismos combatir y, entre ellos, cuáles son los que siguen sustentando pese a todo el proyecto de transformación radical sin radicalidad" (Rozitchner, 2013, p. 26). Sin una radicalización en ese trabajo de subversión personal, sostiene Rozitchner, las categorías de la racionalidad capitalista conservarían su eficacia como determinantes del campo perceptivo en el que se soportan los proyectos emancipatorios.

Por esto mismo, ante las concepciones marxistas que "resaltan el momento objetivo de la estructura de producción, como su único enemigo" (Rozitchner, 2013, p. 26), desechando la transformación subjetiva debido al hecho de ser considerada como mera "subjetividad burguesa" (Rozitchner, 2013, p. 27), Rozitchner se pregunta si la ineficacia política de la revolución no estará dada, precisamente, por haber "generalizado demasiado a la ligera (...) la propia subjetividad como irreductible a toda transformación" (Rozitchner, 2013, p. 26). El filósofo sostiene que es indispensable escrutar nuestros modos de pensar, hacer y sentir como mediación y condición de eficacia para toda acción con pretensiones emancipadoras. Sin el cuestionamiento de estos planos de existencia toda tentativa emancipadora quedaría condenada al fracaso.

La deliberación, la voluntad o la decisión de subvertir el orden societal capitalista, según Rozitchner, debe extenderse hasta alcanzar las variables impensadas de las prácticas sociales y políticas. Por consiguiente, la tarea es complejizar los conceptos de sujeto e ideología de la tradición marxista, añadiendo al tan mentado examen de la conciencia (histórica) las instancias en la que se expresan los conflictos impensados de la subjetividad incon- 
ciente como verificación de las contradicciones del sistema de producción histórico. Puesto que de lo contrario, "lo negado abstractamente [para el caso, que la racionalidad burguesa habite en hombres y mujeres de izquierdas] subsiste y, como nos enseña Freud, nos sigue determinando, sólo que ahora dedicando nuestras energías a que no aparezca" (Rozitchner, 2013, p. 28).

Para Rozitchner, entonces, la necesidad de recurrir al corpus freudiano encuentra sus razones debido a que "las enseñanzas de Freud son importantes para el marxismo y la política porque convergen ratificando, en el análisis del sujeto extendido hasta mostrar las determinaciones del sistema en su más profunda subjetividad, las verdades que Marx analizó en las estructuras objetivas del sistema de producción” (Rozitchner, 2013, p. 29). El filósofo sostiene que es Freud quien encuentra en el seno mismo de la vida subjetiva la eficacia de aquellas categorías con las que se reproduce objetivamente el orden societal capitalista. Por esto mismo, recurre a las cifras de intelegibilidad aportadas por el psicoanálisis freudiano para indagar en la dinámica del sujeto de lo inconciente que se produce al interior del individualismo moderno capitalista.

El pensador argentino retoma el postulado freudiano según el cual "toda psicología individual es, desde siempre y principalmente, psicología social” (Rozitchner, 2008, p. 42). Y esto en vistas a eludir dos extremos: uno donde "predomina exclusivamente una objetividad sin subjetividad" (Rozitchner, 2008, p. 13), y otro donde se tematiza "una subjetividad en la cual lo externo esta reducido y circunscripto sólo a la palabra realidad o mundo exterior" (Rozitchner, 2008, p. 13). En ese marco, a principios de los años 70 el filósofo formula una de sus hipótesis centrales: "el sujeto es núcleo de verdad histórica" (Rozitchner, 2013, p. 28). Esto quiere decir que en el propio cuerpo se verifican, despliegan y debaten los avatares históricos en una tensión entre lo personal y lo impersonal. Para Rozitchner cada uno de nosotros es el lugar de elaboración y constatación de una verdad material más amplia producida en el devenir histórico-colectivo, pero que carecería de consistencia sin la instancia subjetiva como verificadora de sentido/significación. Por lo tanto, logra operar un descentramiento del yo y la consciencia "clara y distinta" para hacer converger lo personal, por fin revalorizado, con lo histórico-colectivo, a los efectos de considerar que "el aparato psíquico no es sino el último extremo de la proyección e interiorización de la estructura social” (Rozitchner, 2013, p. 13).

Para Rozitchner el psicoanálisis freudiano no trataría sino "de explicar la estructura subjetiva como una organización racional del cuerpo pulsión 
por imperio de la forma social" (Rozitchner, 2008, p. 19; cursivas añadidas). Precisamente, la noción de "grieta" elaborada por el filósofo en Freud y los límites del individualismo burgués es empleada para designar la cualidad de la forma-sujeto en el capitalismo. El autor afirma que somos seres fracturados en los cuales se da una articulación histórica de la grieta subjetiva que nos configurado mediante una "distancia interior" (desde y contra el sí mismo) y una "distancia exterior" (entre el supuesto yo cerrado, los otros y el mundo histórico), como correlato de las contradicciones, reificaciones y distancias que atraviesan el nexo social en el capitalismo. El proceso contradictorio del capital es aquel que fragua los conflictos de la "subjetividad inconciente" (Rozitchner, 2013, p. 101).

Las categorías del psicoanálisis freudiano, en la lectura que operamos sobre la teoría de la subjetividad rozitchneriana, son categorías históricas y socialmente generadas. De igual manera en que Postone indica que Marx no se limita al campo de la economía en sentido clásico o disciplinar, Rozitchner sostiene que el pensamiento de Freud no se restringe al campo de la clínica o de la psicología individual, sino que opera la "crítica más dramática e irrefutable del individualismo burgués" (Rozitchner, 2013, p. 68). En nuestro análisis procuramos mostrar la precedencia objetiva de las categorías que buscan criticar la lógica social generalizada de la modernidad capitalista, ya que consideramos que neutralizan la tentativa de basar el diálogo entre psicoanálisis y marxismo en procedimientos abstractos o individualizados propios de una concepción auto-centrada y pura de la subjetividad.

Del mismo modo, intentamos eludir el gesto de sostener nuestras indagaciones teóricas partiendo de la presunta espontaneidad de cierto irreductible teórico (la pulsión, el deseo, la mater, etc.), desde el cual se soportarían los resortes de la crítica y las "promesas emancipatorias" en una presunta realidad psíquica originaria, cuasi-biológica y sustancialista que sería alienada, reprimida o capturada en el capitalismo. Por diversos motivos, entre los que se destaca la crítica a la "hipótesis represiva" formulada por Foucault, esa empresa nos resulta inconducente. La precedencia de las categorías de la lógica del capital posibilitan un intercambio entre marxismo y psicoanálisis desde una crítica auto-reflexiva y radical respecto de sus propias condiciones históricas de emergencia: las formas sociales de mediación capitalista y la forma-sujeto del individualismo burgués.

Partimos de leer a Rozitchner en el marco de la teórica critico-radical del capital aportada por Moishe Postone, como motivo para neutralizar ciertos aspectos de la textualidad rozitchneriana que según nuestra parecer reprodu- 
cen posiciones infértiles de aquello que se denominó "izquierda freudiana" o "freudo-marxismo". Entre ellos, cierta concepción hidráulico-represivista de la dinámica socio-subjetiva que afirmaría la existencia de una realidad pre-social o pre-política, es decir previa a la castración (la dinámica parcial o polimórfica de las pulsiones, o el denominado "niño rebelde freudiano") o anterior al terror paternal (el vínculo infante-materno), basando con ello el horizonte de una proyección emancipatoria en una suerte de política de la memoria que buscaría recuperar las marcas incapturadas de ciertos mecanismos subjetivos resistentes per se a la mediación capitalista. Al mismo tiempo, la inclusión de las tesis rozitchnerianas en el seno de la crítica a la lógica del capital creemos que permite esquivar ciertos lastres categoriales que volverían a Rozitchner un deudor de aquello que Postone menciona como "marxismo tradicional", a saber: cierta concepción sobre la realidad social centrada en el análisis marxista clásico de la lucha de clases y la contradicción entre capital-trabajo que desembocaría en una crítica a la cultura represora desde el punto de vista del deseo y el trabajo. Y por último, la lectura que ensayamos sobre Rozitchner parte de afirmar la preponderancia objetiva de las categorías de la lógica del capital porque entendemos que desarma la posibilidad de sostener las operaciones críticas partiendo de un sujeto a priori resistente, que en ciertos pasajes de la obra rozitchneriana no es sino producto de una mezcla entre una metafísica spinoziana del cuerpopotencia y una visión humanista del sujeto basada en algunos rasgos de los conceptos de ser genérico y alienación pertenecientes a cierta apropiación de los Manuscritos económico-filosóficos de Marx.

Más que las soluciones o respuestas dadas por el autor argentino, nos interesa el campo de problemas que podría viabilizar al interior de la crítica radical del capital. En ese sentido, al igual que Postone señala que hay Historia (Universal) por el "grado" de abstracción social alcanzado por los procesos de mediación que hacen que el capitalismo se configure como una totalidad contradictoria, nuestra hipótesis consiste en afirmar que hay inconsciente (en el estricto sentido en que leemos la re-escritura rozitchneriana del psicoanálisis freudiano) por la eficacia que la dinámica histórica del capital (en sentido postoniano) tiene a nivel subjetivo. Para Postone, la existencia del concepto mismo de Historia (en el sentido progresivo-evolutivo de una Historia Universal comanda por un sujeto global) está históricamente determinado: es resultado de la existencia del capitalismo como lógica social generalizada y auto-propulsada. El "grado" de abstracción y universalidad que caracteriza a la noción teleológica de Historia se erige sobre fondo de los procesos de mediación abstractos, reificados y totalistas concretados en la materialidad 
capitalista. La concepción moderna de la Historia tiene en el funcionamiento civilizatorio del capitalismo sus cifras históricas de emergencia. Según Postone, antes de la modernidad, muy probablemente, se cifraba el devenir humano bajo el concepto de "historias" (en minúscula y en plural), mientras que el moderno concepto de Historia, en singular y en mayúscula, explicita la generalización de una lógica históricamente situada que tiene en el capital el sujeto de lo social. El capital es el principio que motoriza las condiciones históricas de la Historia en cuanto tal, por lo cual esta última responde a la mediación universalizada de formas sociales abstractas que estructuran el nexo social en la civilización capitalista.

Partiendo de esas tesis postonianas, afirmamos que las categorías psicoanalíticas (específicamente, las dispensadas por la teoría rozitchneriana sobre la subjetividad) tienen sus condiciones históricas de posibilidad en la existencia del capitalismo como lógica social generalizada. Tales categorías verifican la eficacia que tienen en la vida subjetiva los procesos de abstracción real y las formas objetivas de dominación impersonal que el capitalismo desarrolla ciegamente a espaldas de los individuos. La mediación de las formas objetivas de dominación que el capital despliega como enfrentadas a la conciencia de los individuos, encuentran su verifacion subjetiva en la lógica de lo inconciente que instituye un sujeto fisurado y des-centrado.

Es por este motivo que argumentamos que nuestra lectura de Rozitchner gira en torno a la hipótesis de que los conceptos freudianos son abstracciones sociales que tienen sus condiciones históricas de posibilidad en los procesos de mediación y dominación impersonal propios de una lógica cuasi-automática y opaca que reifica el nexo social. Sin embargo, esto no implica que no haya lo inconsciente no capitalista (en efecto, Freud mismo relata en La interpretación de los sueños, por ejemplo, la experiencia de lo inconsciente no freudiano), y tampoco que este se diluya en un posible horizonte postcapitalista. Ya que del mismo modo que hay productos del trabajo humano previos al capitalismo, pero que resultan cualitativamente diferentes respecto de la forma mercancía, sostenemos que puede que haya inconsciente antes o después del capitalismo, pero no se encontraría mediado por la ley del valor y la forma-mercancía, o en todo caso no lo estaría en el grado en que ocurre en tales condiciones de producción. Por lo tanto, en la lectura que operamos sobre la teoría rozitchneriana la existencia del procedimiento de lo inconciente está íntimamente relacionada con la mediación y eficacia subjetivante del capital como sujeto social.

En nuestra interpretación del filósofo argentino, las nociones elaboradas por Freud no remiten a construcciones teóricas plenamente positivas que 
buscan adecuarse y captar una realidad psíquica previa a la mediación de la objetividad social. En cambio, asistimos a categorías negativas y autoreflexivas que critican una forma históricamente específica de constitución del sujeto a partir de escrutar los conflictos que signan su devenir histórico. El título del primer libro eminentemente freudiano de Rozitchner, Freud y los límites del individualismo burgués, en cierto modo remite a la configuración límite de la subjetividad en condición capitalista, esto es: el individualismo burgués en tanto forma-sujeto históricamente especifica de la lógica del capital.

En nuestra lectura la existencia del inconsciente responde entonces a la eficacia que adquiere "una lógica histórica [la del capital] que oculta en el campo de lo universal, lo individual y lo subjetivo de lo cual sin embargo resulta" (Rozitchner, 2008, p. 13). Por ende, tal comprensión de la dinámica histórica del capital, tanto como de su correlato inconsciente en la experiencia subjetiva, lleva a que la crítica sobre la forma-sujeto que se construye en la sociedad moderna (el individualismo burgués, en términos rozitchnerianos) sea inescindible de una crítica radical sobre la totalización contradictoria de una lógica social fetichista y reificada propiamente capitalista. Nuestra interpretación se justifica, entonces, en la medida en que consideramos que la crítica filosófica y política sobre la lógica de la moderna civilización capitalista debe complejizarse con una analítica o una terapéutica respecto de la forma-sujeto correspondiente a tal dinámica societal. Allí donde Postone nos ofrece una crítica inmanente del capitalismo, Rozitchner nos otorga una crítica radical sobre la conformación histórica de una subjetividad fetichista y fetichizada como producto de la mediación impersonal de las formas sociales correspondientes a la moderna civilización capitalista.

Por consiguiente, leemos al filósofo argentino buscando explorar la idea según la cual la lógica del capital no solo uniformiza la estratificación social y los contenidos de la conciencia, sino que también media y estructura las categorías del "aparato psíquico". Lo que significa que además de ser un sistema productor de objetos es también una fábrica de subjetividades. En este punto adquiere una relevancia meridiana el análisis rozitchneriano de la forma elemental de la moderna sociedad capitalista: la mercancía. Para Rozitchner la eficacia fetichista remite a un mecanismo automático e impersonal que se instancia en un fetichismo de la mercancía objetivo y una subjetividad fetichizada. Puesto que "cada uno de nosotros ha sido constituido por el sistema de producción histórico, es evidente que el aparato psíquico no hace sino reproducir y organizar ese ámbito individual, la propia cor- 
poreidad, como adecuado al sistema para poder vivir y ser dentro de él” (Rozitchner, 2013, p. 19).

En Freud y el problema del poder, el filósofo argentino recuerda, de manera semejante a Postone, que en condiciones de producción capitalista la dinámica cuantitativa y cualitativamente diversificada de la riqueza material producida en el intercambio universal cooperativo queda encerrada en la forma mercancía. En el citado libro, Rozitchner recupera entonces el mismo contrapunto entre El Capital y los Grundrisse en torno a la categoría de riqueza en la obra de Marx que antes señalamos en Postone. Y esto para remarcar que el capitalismo subsume la posibilidad de toda riqueza social al imperio general de la forma mercancía marcando los objetos y los sujetos sociales con la binariedad contradictoria constitutiva propia del fetichismo mercantil.

Por esto mismo, la totalidad de las existencias particulares llevan consigo inexorablemente los atributos de la mercancía: siendo objetos materiales y sensibles, al tiempo que objetos suprasensibles. Este carácter dual de la mercancía, suprasensible y sensible, hace sistema con una multitud de escisiones que explicitan la binariedad constitutiva del ser capitalista, patentizándose también en la subjetividad: "nuestro propio aparato psíquico, aquel que nos proporciona nuestro propio fundamento (...) es congruente con la forma de aparecer de los objetos sociales" (Rozitchner, 2013, p. 2425). La riqueza social que se produce en la cooperación común y que se cristaliza en las subjetividades humanas como cualificación diversificada de saberes, poderes y atributos sociales, en condiciones capitalista sin embargo asume como propios los atributos de la forma mercancía, configurándose al igual que ésta de un modo limitado, reificado y contradictorio.

La forma de ser del individuo burgués en tanto forma-sujeto del capitalismo "aparece conformado de manera contradictoria: por un parte, en tanto se vive como espíritu, alma o lo que se quiere, aparece contrapuesto en sí mismo con (...) su propio cuerpo, residencia de lo temible en uno mismo que hay que domeñar" (Rozitchner, 2013, p. 24). Ese carácter escindido y conflictivo es lo que caracteriza al aparato psíquico en condiciones capitalista, en la medida en que la estructura misma de lo subjetivo no hace otra cosa que verificar la mediación de las categorías de la lógica social en la inmanencia de la vida individual. La constitución histórica de la formasujeto en el capitalismo patentiza, en su eficacia, "el hecho de que toda relación con la sociedad esté determinada por una forma de objetividad que presenta esa contradicción, nos va señalando que el imperio de una forma contradictoria objetiva determina también su imperio en nuestra propia forma de ser" (Rozitchner, 2013, p. 25). 
Entonces, retomamos las indagaciones de León Rozitchner que buscan constatar la mediación de las categorías propias de la lógica del capital a nivel subjetivo. Para Rozitchner el aparato psíquico freudiano es "una forma mediadora entre el sujeto y la estructura del sistema histórico-social" (Rozitchner, 2008: 33). El problema de la forma de los objetos es complementario con la forma de los sujetos, y esto porque el argentino considera que tal como Marx caracteriza al capitalismo por las contradicciones que lo desgarran, "esta contradicción, expresada como máxima simplificación, determina también la forma de los sujetos" (Rozitchner, 2008:21).

La forma fetichista de la mercancía guarda una conexión interna con una subjetividad fetichizada: lo que "comienza con lo más objetivo, los objetosmercancías, termina con lo más subjetivo, los sujetos-fetichistas" (Rozitchner, 2008: 101). Desde el vamos, por lo tanto, la mediación impersonal de esas formas sociales auto-propulsadas a espaldas de la voluntad conciente de los individuos instituyen un sujeto descentrado y escindido propio de la modernidad capitalista. Estas condiciones históricas hacen que el sujeto de lo inconsciente, en su irreductibilidad y en sus temporalidades, patentice la efectuación a nivel subjetivo de la dinámica impersonal, cuasi-automática y ciega que adopta la lógica histórica. Así pues, la forma dividida y conflictiva de la subjetividad oficia como correlato de la lógica reificada, contradictoria y fetichista que configura el capitalismo.

La lectura que estamos desarrollando sobre la teoría rozitchneriana en el marco de la crítica postoniana de la lógica del capital, creemos que permite ubicar el análisis sobre la subjetividad lejos de un misticismo de lo inconsciente, más allá de una energética espontanea del deseo, allende una posición estructural que concibe lo subjetivo sin tensiones o como efecto residual de una inscripción pasiva en lo simbólico. En nuestra interpretación, Rozitchner concibe la subjetividad a partir de múltiples temporalidades que le permiten mostrar el largo alcance de los procesos de subjetivación (mitologías, monoteísmo, lenguaje, etc.), pero asimismo intenta captar la especificidad histórica de la forma-sujeto en el capitalismo. Y en este último sentido, es posible sostener que la institución de lo inconciente en la vida psíquica verifica la eficacia históricamente determinada de una lógica social que funciona como un sistema de reificación de las relaciones sociales a partir de la mediación universalizada de procedimientos de dominación impersonal que se despliegan automáticamente a espalda de los intereses y representaciones de la conciencia.

La propuesta rozitchneriana, entonces, conduce a comprender la subjetividad capitalista conformada por distancias irresolubles "que la burguesía 
abrió en cada uno de nosotros (...) la cual se resiste en nosotros para ir más allá de los propios límites" (Rozitchner, 2013, p. 23). Las formas de mediación cuasi-objetivas que adopta la dominación y reificación del nexo social bajo la lógica del capital, encuentran ratificación en una construcción fetichizada y agrietada de la subjetividad que se extiende desde un "proceso infantil, individual e imaginario que tendrá vigencia en el proceso real, colectivo y adulto" (Rozitchner, 2008, p. 42).

En ese marco, es posible observar como en diversos momentos de su obra Rozitchner examina un conjunto de experiencias donde la actividad socio-afectiva se encuentra signada por el imperio ambiguo y "despótico" de un principio normativo autonomizado, impersonal e inconciente para los individuos. Leyendo a Rozitchner desde el horizonte de la crítica radical de la lógica del capital, es loable mostrar como el autor se preocupa por desarmar los efectos que conlleva la fetichización de ciertas figuras históricamente relativas (el Yo, el Estado, el Dinero, La Familia, La Revolución, El Padre, etc.) que se absolutizan y des-historizan a tal punto de gobernar la vida de los individuos. Al igual que Postone señala que la ley del valor y la forma-mercancía se presentan como mediadores universales y abstractos que dominan las singularidades, Rozitchner analiza como los procedimientos inconcientes de la subjetividad producen figuras pretendidamente independientes y exteriores que subyugan de manera ciega, impersonal y cuasi-automática las voluntades y representaciones conscientes que sigan la acción humana.

Hemos observado, entonces, que Rozitchner procura contribuir a la tradición marxiana verificando la mediación y la eficacia que tienen, en la vida psíquica, las categorías de la crítica de la economía política mediante una lectura sobre las categoriales del psicoanálisis freudiano. El examen filosófico de la historicidad conflictiva y agrietada del aparato psíquico propiciado por el psicoanálisis freudiano, según nuestra interpretación, hacen que el pensamiento rozitchneriano complejice la teoría crítica del capital con las cifras de lo inconciente. $\mathrm{Y}$ es por ello que en nuestro trabajo intentamos mostrar como el filósofo argentino agrega al estudio que Postone opera sobre la lógica objetiva del capital, una crítica radical y pormenorizada sobre la forma-sujeto que se construye en el capitalismo. Finalmente, creemos que esto resulta indispensable para todo proyecto con pretensiones de transformación radical de la sociedad en la medida en que los límites que facturan la forma del individualismo burgués en el capitalismo revelan un problema que se debería ubicar en el centro de toda política emancipatoria. 


\section{A modo de conclusión}

Luego de analizar, por un lado, la "relectura categorial" de la lógica del capital desarrollada por Moishe Postone, y por el otro, la lectura filosófica del psicoanálisis freudiano dispensada por Leon Rozitchner, provisoriamente concluimos lo siguiente: a) el capital es el sujeto de una lógica histórica contradictoria y tendencialmente totalista; b) la construcción histórica de la subjetividad en el capitalismo adopta la forma (inconciente) de una dinámica conflictiva, despótica y agrietada que nos configura de acuerdo a una lógica social contradictoria, impersonal y cuasi-automática; c) tanto Rozitchner como Postone buscan realizar una crítica radical de la sociedad capitalista y del individualismo burgués, señalando la necesidad de componer otros modos del nexo social e imaginar nuevos procesos de subjetivación política, asumiendo nuestro estar constituidos por aquello mismo que deseamos enfrentar; y por último, d) la categoría critico-negativa de rique$\mathrm{za}$, recuperada por ambos autores luego de una lectura contrapuesta entre El capital y los Grundrisse de Marx, habilita pensar que las condiciones del cambio singular y de la transformación social emergen en la inmanencia de las posibilidades que el mismo movimiento del capital genera, pero ocluye, al reificar las relaciones objetivas y fetichizar lo subjetivo.

\section{Bibliografía}

Acha, O., Freud y el problema de la historia, Buenos Aires, Prometeo, 2007. Althusser, L., Ideología y aparatos ideológicos del Estado. Freud y Lacan, Buenos Aires, Nueva Visión, 2011.

Bosteels, B., Marx y Freud en América Latina. Política, psicoanálisis y religión en tiempos de terror, Madrid, Akal, 2016.

Deleuze, G. \& Guattari, F., El Anti-Edipo, Barcelona, Paidós, 2010.

Foucault, M., Historia de la Sexualidad I. La voluntad de saber, Buenos Aires, Siglo XXI, 2011.

Grüner, E., "El psicoanálisis no es el marxismo, pero...", Ideas de Izquierda 5 (2013), 31-35.

Marx, K., Elementos fundamentales para la crítica de la economía politica (Grundrisse) 1857-1858, Tomo I, México, Siglo XXI, 1971.

Marx, K., El capital, Buenos Aires, Siglo XXI, 2012.

Masotta, O., Conciencia y estructura, Buenos Aires, Eterna Cadencia, 2010. Postone, M., Tiempo, trabajo y dominación social, Madrid, Marcial Pons, 2006. 
Ricoeur, P., El conflicto de las interpretaciones, Buenos Aires, Fondo de Cultura Económica, 2003.

Rozitchner, L., Freud y el problema del poder, Buenos Aires, Losada, 2008. Rozitchner, L., Frend y los limites del individualismo burgués, Buenos Aires, Biblioteca Nacional, 2013. 